\title{
The correlates of physical activity among the population aged $50-70$ years Determinantes de la actividad física entre las personas de 50 a 70 años
}

*Fernando Lera-López, **Mirian A. Garrues Irisarri, ***María José Suárez Fernández *Universidad Pública de Navarra (España), **Universidad del País Vasco (España), ***Universidad de Oviedo (España)

\begin{abstract}
Background: Physical activity is of particular interest due to its potential for improving quality of life and reducing health care costs. The contribution of this paper is to analyse the correlates of physical activity (PA) among individuals aged 50-70 years old. We differentiate between physical activity during leisure time (LTPA) and total physical activity (Total PA) and besides we offer potential policy advice to increase PA. Methods: We use a cross-sectional survey from a sample of Spanish individuals between 50 and 70 years of age. We analyse the correlates of LTPA and Total PA by estimating ordered probit models including socio-demographic characteristics, health and emotional wellbeing and social support. Results: The covariates explain in different ways LTPA and Total PA levels. In particular, the accomplishment of a minimum of LTPA is positively related to partner participation in LTPA $(\mathrm{p}<0.01)$, a good life satisfaction $(\mathrm{p}<0.01)$, being male $(\mathrm{p}<0.01)$ and secondary education completion $(\mathrm{p}<0.02)$; and it is negatively related to working status $(\mathrm{p}<0.01)$. On the contrary, very high levels of total PA are positively associated with partner participation $(\mathrm{p}<0.01)$, self-perceived health $(\mathrm{p}<0.01)$, women $(\mathrm{p}<0.01)$ and working status $(\mathrm{p}<0.05)$. Conclusions: It is important to increase male energy expenditure in other life domains besides leisure time. Regarding women, social support seems necessary to reach minimum levels of LTPA. Finally, the socialisation effect that we have obtained as well as the positive impact of the extrinsic social support variables might suggest the necessity to take into account couple and family variables.
\end{abstract}

Keywords: Physical Activity, leisure activity, aging, health, personal satisfaction, nonlinear models.

Resumen. Introducción: La realización de actividad física (AF) es de una indudable importancia social dado sus efectos positivos sobre la salud. Este trabajo pretende analizar los determinantes de la AF de individuos de 50-70 años. Metodología: Se emplea un estudio observacional transversal a partir de una muestra de españoles entre 50 y 70 años. Se analizan los determinantes de la AF en el tiempo libre y el total de AF mediante modelos probit ordenados, incluyendo las características sociodemográficas, de percepción de la salud física, del estado emocional y del apoyo social. Resultados: Los determinantes del total de AF y la AF realizada en el tiempo libre son distintos. La realización de un mínimo de AF en el tiempo libre está relacionada positivamente con ser hombre $(\mathrm{p}<0.01)$ y tener estudios secundarios $(\mathrm{p}<0.02)$, la participación de la pareja $(\mathrm{p}<0.01)$ y una buena satisfacción ante la vida ( $<<0.01$ ); y negativamente con el estatus laboral ( $<<0.01)$. Por otro lado, altos niveles de AF están asociados a ser mujer ( $<<0.01$ ), el estatus laboral $(p<0.05)$, el nivel de salud percibida $(p<0.01)$ y la participación de la pareja $(p<0.01)$. Conclusiones: En el caso de los hombres, es importante incrementar la $\mathrm{AF}$ en otros ámbitos fuera del tiempo libre. En el caso de la mujer, el apoyo social resulta necesario para alcanzar unos niveles saludables de AF. Finalmente, el efecto de la socialización y el apoyo social extrínseco resultan variables relevantes que plantean la necesidad de desarrollar políticas de promoción teniendo en cuenta la situación familiar y de la pareja.

Palabras clave: Actividad física, actividad de ocio, envejecimiento, salud, satisfacción personal, modelos no lineales.

\section{Introduction}

Physical Activity (PA) represents a broad term that encompasses activities that increase the energy expenditure undertaken during different domains of daily life. In 2010 the World Health Organisation, based on previous evidence, established «The global recommendations of PA for health» (WHO, 2010). Different ordinal categories of energy expenditure to achieve PA, including the minimum level, were determined.

The close relationship between reported Total PA, PA at leisure time (LTPA) and health outcomes (presence of chronic diseases, activity limitations, self-rated health or use of sanitary services) has been widely emphasised in different studies with general populations (CimarrasOtal et al., 2014; Gebel et al., 2015; Paterson, Jones, \& Rice, 2007). The period of later midlife and older age is characterized by an increase in the prevalence of chronic medical conditions (Prince et al., 2014) and associated disabilities (Jia \& Lubetkin, 2016; Klijs, Nusselder, Looman, $\&$ Mackenbach, 2011). Data confirm the importance of regular PA for both prevention and management of chronic non-communicable diseases or conditions, even when initiating PA in later life (Cimarras-Otal et al., 2014; Morrow-Howell et al., 2014; Paterson et al., 2007). Nevertheless, the number of individuals in the general population of developed countries reporting engagement in PA has stopped or decreased over the last years (Berg, Warner, \& Das, 2015; CIS, 2014; Moore, Harris, Carlson, Kruger, \& Fulton, 2012).

In this context, it is absolutely necessary to have a better understanding of the PA correlates. Several reasons could be argued to concentrate on older adults as the target group for improving the amount of PA. First, the increasing number and percentage of older adults in the population in many developed countries is of great concern. In Spain, the population over 65 years of age was near $20 \%(18.2 \%)$ in 2014 , and

Fecha recepción: 13-05-16. Fecha de aceptación: 20-09-16 Fernando Lera López lera@unavarra.es it will probably increase until nearly a quarter of the population by 2029. By 2064, it is estimated that more than one-third (38.7\%) of the Spanish population will be over 65 (INE, 2014). Second, despite the increased longevity of the older population, healthy life years, health related quality of life, mobility and functionality of the older population still represents a health challenge (Christensen, Doblhammer, Rau, \& Vaupel, 2009). The prevalence of chronic disease, mobility limitations and functional dependence increases as we age (Cesari et al., 2013; Curb et al., 2006). However, at the same time, regular PAin the older population has significant and positive effects on health outcomes, including longevity, prevention and management of chronic illness and conditions, occurrence of adverse events -falls, institutionalisation- (Arem et al., 2015; Taylor et al., 2004) as well as on the control of medical costs (Ackermann et al., 2008). Although most people know the benefits of engaging in regular PA, the major part of the older population do not establish a regular PA leisure time routine. Additionally, the quantity and/or intensity of PAnormally decreases with age (Cabane \& Lechner, 2014; Chau et al., 2013; Godfrey et al., 2014). In the case of Spain, the level of LTPA has decreased since 2006 (Casado-Pérez et al., 2015a). The measure of PAat the population level is useful for health promotion initiatives and policy development, in particular in older adults (Müller, Ansari, Ale Ebrahim, \& Khoo, 2015).

There are two surveys in Spain that analyse the level of PA of adults using quantitative variables at local level. López Munera et al. (2016) analyse the total level of PA (high, moderate and low) in the province of Jaen. The study of Romero et al. (2010) assesses the level of physical activity at leisure time of the Sevillian adult population and its relationship to their health status perception. Other previous surveys by Palacios-Ceña et al. (2011, 2012), Alonso-Blanco et al. (2012), and Casado-Pérez et al. (2015a, b) have focused on general population. For example, Palacios-Ceña et al. (2006, 2011 and 2012) have studied the PA domain at leisure time using a non-quantitative variable. CasadoPérezetal. (2015a), despite they make a difference between the intensity at PA, they do not make distinction among the different domains of 
daily life. Finally, Alonso-Blanco et al. (2012) analyse the correlates of PA in leisure time and at the work site. Considering this previous empirical evidence, the purpose of this study is the estimation of social, demographic, self-perceived health, and satisfaction with life status that contribute to explain the degree of physical activity (PA) of older adults and young seniors (50-70 years), focusing on the total level of PA and PAat leisure time (LTPA).A better knowledge about these correlates might help to elaborate particular policies and strategies to boost PA in general, and in particular, during leisure time for specific groups of age.

\section{Methods}

\section{Database}

The database used in this paper is based on the Physical Activity, Health and Well-being Survey (PAHWS) carried out by the authors and financed by the National Sport Council, the national sports body in Spain (CSD). A pre-test was developed to check the validity of the questionnaire and the reliability of the survey. From a national population of 10.5 millions of people between 50 and 70 years (INE, 2014), 1,283 contacts with interviewees were made. Finally, 800 interviews to community living older participants were completed, with a 62 per cent survey response rate. If we consider only the number of interviews rejected $(n=38)$, the response rate estimated was 95.4 per cent. The participants were selected from the seventeen Spanish regions and its distribution is based on stratified sampling of municipalities (four different categories of population size), with gender and age interval (four intervals, 50-54, 55-59, 60-64 and 65-70) proportions reflecting the national and regional populations.

\section{Studied population}

To estimate the sample size we consider a sampling error of 3.5 per cent and a confidence level of 95.5 per cent, usually applied in many studies. Using these values and taking into account a population of 10.5 millions of Spanish people between 50 and 70 years, the sample was estimated in 784 individuals -see Santesmases Mestre (2001) and Mateu and Casal (2003) for more details about how to estimate sample sizes-

Due to the financial restrictions of the project financed by the CSD, we decided to establish a sample of 800 individuals. After the selection of the sample, the survey was conducted in October and November 2012 by means of computer-assisted telephone interviewing (CATI system). This system allows us to contact directly with the individuals through their telephone numbers. A market research firm provided the collection of information. According to the "Guidelines for Data Processing and Analysis" of the International Physical Activity Questionnaire (IPAQ), all those that exceed 16 hours/day of PA (35 individuals) were excluded from the sample of 800 subjects. We also dropped those people with serious problems with personal care, walking or other daily activities, because they could not consider doing any kind of physical activity, and those who did not provide information on all variables used in our empirical analysis. Therefore, the final sample size is 709 individuals.

\section{Variables}

Dependent Variables: Total Physical Activity Level and During Leisure Time

The IPAQ (International Physical Activity Questionnaire) was selected because it has been validated and tested for administration between 15-69 years of age (Hurtig-Wennlöf, Hagströmer, \& Olsson, 2010), including the Spanish version of the questionnaire (RománViñas et al., 2010). We use the long version (31 items), validated for the Spanish population (Román-Viñas et al., 2010; Román Viñas, Ribas Barba, Ngo, \& Serra Majem, 2012). Different studies have shown that reliable and valid physical activity data can be collected using the long IPAQ questionnaire (Booth et al., 2003; Hagströmer, Oja, \& Sjöström, 2006). This study focuses on Total PA and specially LTPA because these variables are the ones that are significantly related to self-perceived health (Cohen, Baker, \& Ardern, 2016).
Self-reported data from IPAQ-Long was employed to calculate the Metabolic Energy Expenditure of Tasks (METs) during a week (in minutes'sem-1) as a continuous variable (METs $\cdot \mathrm{min} \cdot \mathrm{sem}-1)$ for Total PA (Booth et al., 2003; Lera-López et al., 2016 In press). Total PA represents the addition of energy expenditure collected at four different life domains (work, active transportation, domestic and gardening, and leisure time; Table 1). The questionnaire takes into consideration the type and intensity of the activity for each domain (walk, moderate or vigorous), time spent ( $\mathrm{min}$ ) and the frequency (days per week) (Ainsworth etal., 2000; Hagströmer et al., 2006) (See Table 1). Following this approach, this study focuses on Total PA and PA developed during leisure time (LTPA).

\begin{tabular}{|c|c|c|c|c|c|}
\hline Domain & Domain Intensity & METs & $\begin{array}{l}\text { Time per } \\
\text { day (min) }\end{array}$ & $\begin{array}{l}\text { Frequency } \\
\text { (days per } \\
\text { week) }\end{array}$ & $\begin{array}{c}\text { Total } \\
\text { METs } \cdot \text { min }^{-} \text {sem }^{-1} \\
\text { Domain }\end{array}$ \\
\hline \multirow{3}{*}{1 Work } & 1a Vigorous & 8.0 & per & Per & at Work= Sum of \\
\hline & $1 \mathrm{~b}$ Moder & 4.0 & & Per & Vigorous + Moderate \\
\hline & 1c Walk & 3.3 & er & Per & +Walk METs-min $\cdot$ week $^{-1}$ \\
\hline \multirow{2}{*}{$\begin{array}{l}2 \text { Active } \\
\text { transportation }\end{array}$} & 2a Cycle & 6.0 & per & Per & $\begin{array}{l}\text { at Active } \\
\text { transportation= Sum of }\end{array}$ \\
\hline & $2 \mathrm{~b}$ Walk & 3.3 & per & Per & 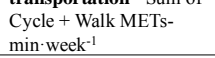 \\
\hline \multirow{3}{*}{$\begin{array}{l}3 \text { Domestic and } \\
\text { gardening (yard) } \\
\text { activities }\end{array}$} & $\begin{array}{l}\text { 3a Vigorous yard } \\
\text { chores }\end{array}$ & 5.5 & per & Per & \multirow{3}{*}{$\begin{array}{l}\text { at Domestic and } \\
\text { gardening= Sum of } \\
\text { Vigorous yard chore }+ \\
\text { Moderate yard chores }+ \\
\text { Moderate inside chores } \\
\text { METs-min } \cdot w^{-} e^{-1}\end{array}$} \\
\hline & $\begin{array}{l}\text { 3b Moderate yard } \\
\text { chores }\end{array}$ & 4.0 & per & Per & \\
\hline & $\begin{array}{l}\text { 3c Moderate } \\
\text { inside chores }\end{array}$ & 3.0 & per & Per & \\
\hline \multirow{3}{*}{4 Leisure Time } & 4a Vigorous & 8.0 & per & Per & at Leisure time $=$ Sum of \\
\hline & & & & & \\
\hline & 4c Walk & 3.3 & per & Per & Walk METs-min $\cdot$ week $^{-1}$ \\
\hline \multicolumn{6}{|c|}{$\begin{array}{l}\text { Adapted from Craig (Booth, Ainsworth, Pratt, Ekelund, Yngve, Sallis and Oja 2003) based on } \\
\text { estimated Metabolic Equivalent of Tasks (METs) on the updated Compendium of Physical } \\
\text { Activities (Ainsworth, Haskell, Whitt, Irwin, Swartz, Strath, O Brien, Bassett, Schmitz and } \\
\text { Emplaincourt 2000) METs, Metabolic equivalent of tasks, TOTAL PA METs min } \cdot \text { sem }^{-1} \text { is } \\
\text { equivalent to computing the sum of Total METs min } \text { week }^{-1} \text { scores at work }+ \text { active } \\
\text { transportation +.domestic and gardening + Leisure time. }\end{array}$} \\
\hline
\end{tabular}

Based on previous recommendations of Total PA for health (Hamrik, Sigmundová, Kalman, Pavelka, \& Sigmund, 2014; Haskell et al., 2007; WHO, 2010), four different levels of energy expenditure in PA were obtained from the categorisation of continuous METs $\cdot \min \cdot \mathrm{sem}-1$ for Total PA and LTPA: 1) Low (<600), 2) moderate (600-1499), 3) high, (1500-3000) and 4) very high (>3000). We will refer to these ordinal variables as Total PA-Level and LTPA-Level, respectively. Although we have a continuous measure of PA, we have defined our dependent variables as ordinal to decrease the degree of overestimation of physical activity obtained by self-reported methods (Medina, Barquera, \& Janssen, 2013).

\section{Covariates}

The covariates included in our study could be classified in three groups that support the dose of achievement at Total and LTPA-Level: 1) self-perceived health and emotional well-being 2) inherent social and demographic variables and 3) extrinsic social support for PA.

Self-reported health: perceived health and emotional well-being

The EQ-5D-5L instrument was employed to calculate health related quality of life as a single index of health (from -0.654 to 1 ), where -0.654 represents the lowest value and 1 the highest perception of health (Weijnen etal., 2006). The index was obtained from five dimensions of health: 1) mobility, 2) self-care, 3) usual activities, 4) pain/discomfort and 5) depression anxiety. Pain-discomfort was included in the model because is frequently associated to chronic health conditions. The response at each dimension ranges from one to five levels of severity, one equals the lowest level and five the highest level. This EQ-5D-5L instrument has been applied in more than 15 countries in the last three years and has proved useful in different comparative analyses (Szende, Janssen, \& Cabases, 2014).

Using the same methodology applied by the World Value Surveys, a well-known survey in use since 1981 in more than 100 countries (Veenhoven, 2003), subjective well-being was measured as the level of individual life satisfaction. In particular, life satisfaction was addressed in the question: 'Taking all things considered, how satisfied are you with your life as a whole these days?' The level of life satisfaction is 
measured as a 1-10 Likert-type scale, from completely dissatisfied to completely satisfy. From this information, we define a dummy equal to one if the level of satisfaction is higher or equal to six in order to avoid the problem of a low sample size in some categories.

Measures of subjective well-being meet a sufficient scientific standard in terms of internal consistency, validity, reliability, and a high degree of stability over time (Frey \& Stutzer, 2002). In particular, life satisfaction has been widely used in previous studies to analyse wellbeing (Haller \& Hadler, 2006; Wang \& Wong, 2014).

\section{Inherent Socio-demographic variables}

For our analysis, we used these socio-demographic variables: age (chronological age), gender, marital status (married versus other marital status), educational level completed (secondary and university education, the lowest educational level was the base category), working status (a dummy equal to one if the individual is working), and income (in four different levels, the lowest level of income was the base category). Previous studies typically examine individual participation in PA focusing on individual characteristics including gender, age, educational level, income and occupation, marital status or working time (Marques et al., 2014; Mesters, Wahl, \& Van Keulen, 2014; Meyer, Rezny, Breuer, Lamprecht, \& Stamm, 2005).

\section{Extrinsic social support}

Two non-inherent variables were also included: medical advice for $P A$ participation and partner participation in $P A$.

\section{Results}

\section{Descriptive analysis of Total PA and LTPA}

The descriptive statistics for Total PA and for the four domains (LT, work, active transportation and household), taking into consideration $600 \mathrm{METs} \cdot \mathrm{min} \cdot \mathrm{sem}^{-1}$, are represented in Table 2 by gender. The table also shows the percentage of the sample that meet PAcut-off criterion for the rest of the covariates in the study.

The figures in Table 2 show that PA is mainly performed during leisure time and household activities, but the relevance of these domains vary between men and women. Males are more physically active during leisure time than women, whereas the percentage of females exerting
Table 2

Minimum level of PA for health in Total and the same level at LT, at main variables

\begin{tabular}{|c|c|c|c|c|c|c|}
\hline \multirow{2}{*}{ Variable } & \multirow[b]{2}{*}{ Unit } & \multirow{2}{*}{$\begin{array}{c}\begin{array}{c}\text { Total } \\
\text { sample }\end{array} \\
\mathrm{N}=709\end{array}$} & \multicolumn{2}{|c|}{ Total PA $\geq 600$} & \multicolumn{2}{|c|}{ LTPA $\geq 600$} \\
\hline & & & $\begin{array}{c}\text { Male } \\
(\mathrm{N}=323)\end{array}$ & $\begin{array}{l}\text { Female } \\
(\mathrm{N}=357)\end{array}$ & $\begin{array}{c}\text { Male } \\
(\mathrm{N}=216)\end{array}$ & $\begin{array}{c}\text { Female } \\
(\mathrm{N}=186)\end{array}$ \\
\hline
\end{tabular}

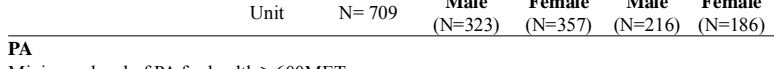

Minimum level of PA for health $\geq 600 \mathrm{MET}$

LTPA

Work PA

Transportation PA

Household-PA

Covariates

Social demographic

Male

Female

Married

Educational level
completed

completed

Sec Ed
University Degree

University Degree
Income monthly $(\epsilon)$

$1001-1700$

$1701-2800$

$2801-4000$

$>4000$

Working status

Health and emotional

well being

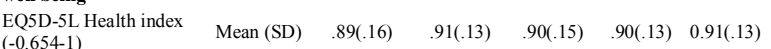

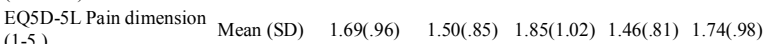

$\begin{array}{lcccccc}(1-5) & 0 & 40.8 & 30.3 & 49.0 & 29.2 & 44.1\end{array}$

$\begin{array}{lllllll}\text { Life satisfaction } 0-10 & \% & 76.9 & 81.4 & 73.1 & 83.8 & 80.6\end{array}$

$\begin{array}{lllllll}(\geq 6) & \% & 76.9 & 81.4 & 73.1 & 83.8 & 80.6\end{array}$

$\begin{array}{lllllll}\text { Extrinsic social support } & \% & 53.9 & 55.1 & 53.2 & 57.9 & 55.4\end{array}$

\begin{tabular}{lllllll} 
Medical advice for PA & $\%$ & 53.9 & 55.1 & 53.2 & 57.9 & 55.4 \\
Partner participation in & $\%$ & 30.0 & 33.1 & 28.6 & 38.0 & 35.5 \\
\hline
\end{tabular}

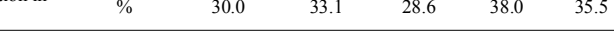

$\mathrm{N}=$ Total sample, $\mathrm{n}=$ sample that meet cut point, Work $\mathrm{PA}=\mathrm{PA}$ at work (represents walk, moderate, vigorous $\mathrm{PA}$ ); Transportation-PA= active transportation (walk, biking), Household $\mathrm{PA}=$ domestic (moderate) and gardening (moderate, vigorous), LTPA= Leisure time physical activity (walk, moderate, vigorous). Sec Ed= Secondary Education, Sports partner= Partner participation in PA, Medical advice $=$ Medical advice for exercise

physical effort for household chores is very high. Regarding covariates, most of the sample is married and have not completed secondary education. In addition, men tend to be more educated than women. Income falls mainly between 1,000 and 2,800 euros per month. Over a third of the sample is working; males are more likely to be working than females. Mean values of self-perceived health and life satisfaction are high, and there are not significant gender differences in the average value of these variables. About one third of the sample states that their partners take part in LTPA.

\section{Statistical Analysis}

Given that our dependent variables (Total PA and LTPA) are ordinal, we estimate ordered probit models to examine the relationships among the variables and the covariates.

The specification of ordered probit models starts from a continuous latent variable, $y_{i}{ }^{*}$, that is a linear function of the covariates, $\boldsymbol{x}_{i}$ (Wooldridge, 2010).

$$
y_{i}^{*}=\boldsymbol{x}_{\boldsymbol{i}} \boldsymbol{\beta}+\varepsilon_{i}
$$

where $\boldsymbol{\beta}$ is the vector of parameters to be estimated and $\varepsilon_{1}$ is a random term that follows a standard normal distribution. The dependent variable takes four values depending on the value of the continuous latent variable $\left(\mathrm{METs} \cdot \mathrm{min}^{\mathrm{sem}} \mathrm{se}^{-1}\right)$ :

$$
\begin{gathered}
y_{i}=1 \text { if } \quad y_{i}^{*} \leq \alpha_{1} \\
y_{i}=2 \text { if } \alpha_{1}<y_{i}^{*} \leq \alpha_{2} \\
y_{i}=3 \text { if } \alpha_{2}<y_{i}^{*} \leq \alpha_{3} \\
y_{i}=4 \text { if } \quad y_{i}^{*}>\alpha_{3}
\end{gathered}
$$

In the previous equation, $\alpha_{1}, \alpha_{2}, \alpha_{3}$ are the cutoff points. Thus, the probabilities of observing each value of the dependent variables are defined as follows:

$$
\begin{gathered}
\operatorname{Pr}\left(y_{i}=1\right)=\phi\left(\propto_{1}-\boldsymbol{x}_{\boldsymbol{i}} \boldsymbol{\beta}\right) \\
\operatorname{Pr}\left(y_{i}=2\right)=\phi\left(\propto_{2}-\boldsymbol{x}_{\boldsymbol{i}} \boldsymbol{\beta}\right)-\phi\left(\propto_{1}-\boldsymbol{x}_{\boldsymbol{i}} \boldsymbol{\beta}\right) \\
\operatorname{Pr}\left(y_{i}=3\right)=\phi\left(\propto_{3}-\boldsymbol{x}_{\boldsymbol{i}} \boldsymbol{\beta}\right)-\phi\left(\propto_{2}-\boldsymbol{x}_{\boldsymbol{i}} \boldsymbol{\beta}\right) \\
\operatorname{Pr}\left(y_{i}=4\right)=1-\phi\left(\propto_{3}-\boldsymbol{x}_{\boldsymbol{i}} \boldsymbol{\beta}\right)
\end{gathered}
$$

where $\Phi$ is the standard normal distribution function. The log likelihood function is:

$$
\log L=\sum_{i} \sum_{j=1}^{4} \log \operatorname{Pr}\left(y_{i}=j\right)^{d_{i j}}
$$

being $d_{i j}$ dummy variables equal to one when the dependent variable is equal to $j$.

The parameters $\boldsymbol{\beta}$ are estimated by maximum likelihood, as well as the t-statistics of the ordered probits for Total PA-Level and LTPALevel. To get a deeper insight into the effect of the covariates, we have also computed the individual marginal effects. Statistical analyses were performed using Stata.

Given the small sample size of the survey, we consider a variable is significant at $10 \%$ significance level. 


\begin{tabular}{|c|c|c|c|c|c|c|c|c|c|c|c|}
\hline \multirow[t]{2}{*}{ Covariates } & \multicolumn{3}{|c|}{ Ordered Probits for Total METs } & \multicolumn{2}{|c|}{$y=1<600 M E T s(4.09 \%)$} & \multicolumn{2}{|c|}{$\begin{array}{c}y=\underset{(8.06 \%)}{260-1499} \text { METs } \\
\text { (106) }\end{array}$} & \multicolumn{2}{|c|}{$\begin{array}{l}y=31500-2999 \\
\text { METs }(17.49 \%)\end{array}$} & \multicolumn{2}{|c|}{$\begin{array}{c}y=4 \geq 3000 \\
\text { METs }(68.82 \%)\end{array}$} \\
\hline & $\beta$ Coef. & t-Student & $p$ value & $d y / d x$ & SD & $d y / d x$ & SD & $d y / d x$ & SD & $d y / d x$ & SD \\
\hline \multicolumn{12}{|l|}{ Social and demographic } \\
\hline Age & -.2778 & -1.44 & .151 & .001 & .001 & .002 & .001 & .003 & .001 & -.006 & .003 \\
\hline $\mathrm{Age}^{2}$ & .0022 & 1.36 & .175 & & & & & & & & \\
\hline Male & -3466 & -3.46 & .001 & .028 & .009 & .040 & .012 & .046 & .013 & -.114 & .032 \\
\hline Marital status (married) & -.0154 & -0.12 & .903 & .001 & .010 & .002 & .014 & .002 & .017 & -.005 & 042 \\
\hline \multicolumn{12}{|c|}{ Educational level completed } \\
\hline Sec. education & -.0917 & -0.71 & .475 & .008 & .011 & .011 & .015 & .012 & .017 & -.030 & .042 \\
\hline Univ. education & -.2579 & -1.75 & .080 & .021 & .012 & .030 & .017 & .034 & .020 & -.085 & .048 \\
\hline \multicolumn{12}{|l|}{ Income monthly $(€)$} \\
\hline $1001-1700$ & .0043 & .03 & .974 & -.000 & .011 & -.000 & .016 & -.001 & .018 & .001 & .045 \\
\hline $1701-2800$ & -.0292 & -.21 & .837 & .002 & .012 & .003 & .016 & .004 & .019 & -.010 & .047 \\
\hline $2801-4000$ & -.2454 & -1.13 & .257 & .020 & .018 & .028 & .025 & .033 & .029 & -.081 & .071 \\
\hline$>4000$ & -.2464 & -1.05 & .296 & .020 & .020 & .028 & .027 & .033 & .031 & -.081 & .078 \\
\hline Working status & .2392 & 1.97 & .049 & -.020 & .010 & -.027 & .014 & -.032 & .016 & .079 & .040 \\
\hline \multicolumn{12}{|c|}{$\begin{array}{l}\text { Health and emotional well } \\
\text { being }\end{array}$} \\
\hline Health index & 1.0065 & 3.53 & .000 & -.083 & .026 & -.116 & .035 & -.134 & .038 & .332 & .092 \\
\hline Pain & -.0532 & -.52 & .604 & .004 & .008 & .006 & .012 & .007 & .014 & -.018 & .034 \\
\hline Life satisfaction & .0585 & .50 & .615 & -.005 & .010 & -.007 & .013 & -.008 & .015 & .019 & .038 \\
\hline \multicolumn{12}{|l|}{ Extrinsic social support } \\
\hline Medical advice & .0283 & .29 & .770 & -.002 & .008 & -.003 & .011 & -.004 & .013 & .009 & .032 \\
\hline PA (partner) & .3272 & 2.82 & .005 & -.027 & .010 & -.038 & .014 & -.043 & .015 & .108 & .038 \\
\hline $\begin{array}{l}\log L \\
\text { Pseudo } R^{2}\end{array}$ & \multicolumn{11}{|c|}{$\begin{array}{l}-610.1911 \\
.0412\end{array}$} \\
\hline $\begin{array}{l}P_{\text {seudo }}{ }^{2} \\
\text { Sample size }\end{array}$ & & & & & $\begin{array}{c}.041 \\
705\end{array}$ & & & & & & \\
\hline
\end{tabular}

Note: METs represents METs $\cdot \min \cdot \mathrm{sem}^{-1}$

\section{Explanatory variables for Total PA-Level}

Table 3 shows the parameters and $t$-statistics of the ordered probits for Total PA-Level, as well as the mean and standard deviations of the individual marginal effects. The signs of the ordered probit coefficients provide some information about the effect of the covariates on the dependent variable but, as the relationship is not linear, the coefficients are not the marginal effects. If the coefficient is positive, the variable increases the probability of observing the highest level of energy expenditure in Total PA (>3000 METs $\left.\cdot \mathrm{min} \cdot \mathrm{sem}^{-1}\right)$ and reduces the probability of not achieving the minimum level of Total PA for health $\left(<600 \mathrm{METs} \cdot \mathrm{min} \cdot \mathrm{sem}^{-1}\right)$; the opposite happens if the coefficient is negative. However, the coefficients do not give any information on the effect of the variable in the intermediate levels of PA.

According to our results, age reduces the probability of a high level of Total PA. In the case of age, we performed Likelihood Ratio tests about the joint significance of age and age squared. Males and graduates are more likely to develop a low level of PA. Workers are more likely to achieve the highest level of PA, as well as people whose partners participate in LTPA. The score of self-perceived health is positively associated with the probability of reaching a high level of Total PA. In fact, this is the variable with the greatest marginal effect in all categories - in absolute value. Income, life satisfaction, medical advice and suffering from pain are not significantly related to the total level of energy expenditure.

\section{Explanatory variables for LTPA-Level}

LTPA-Level coefficients and marginal effects are presented in Table 4. Age is not a significant covariate in this case, but gender, education, working status, health, partner participation during leisure time, income and life satisfaction are relevant factors in explaining LTPA.

The average marginal effects show that males and individuals with more education are more likely to cover the minimum requirements of LTPA-Level. However, workers and people with the highest family income tend to be less active at the LTPA-Level. Regarding health and life satisfaction, both of these covariates are positively related to higher levels of LTPA, whereas pain has a negative association. Finally, if the partner participates in LTPA the probability of being physically active at leisure is higher; this is variable with the highest marginal effect, followed by the health index.

\section{Discussion}

Our findings identify a specific group of the Spanish older adult population who is at particular risk of low levels of Total PA for health (less than $600 \mathrm{METs} \cdot \mathrm{min} \cdot \mathrm{sem}^{-1}$ ). The same cut point of energy expenditure was applied to LTPA in order to identify associated covariates of a high or low degree of activity in leisure time. This study reveals some interesting socio-demographic differences when comparing the correlates at Total PA-Level and LTPA-Level. First, gender has the opposite relationship on the dependent variables. Males are less physically active than females when considering Total PA but their energy expenditure is greater during leisure time. This finding is not in accordance with previous findings in other countries or cultures (Murtagh et al., 2015) and in Spain (Alonso-Blanco et al., 2012; Casado-Pérez et al., 2015a,b) but it is partially similar to those of Moschny, Platen, Klaaßen-Mielke, Trampisch, \& Hinrichs (2011) and Palacios-Ceña et al. (2011 and 2012). These authors reveal that the engagement in LTPA is comparable between men and women but men spend more time in LTPA; in contrast, time spent at domestic chores is similar between sexes (Moschny, Platen, Klaaßen-Mielke, Trampisch, \& Hinrichs, 2011). The result obtained in our study might suggest that, in the case of Spain, many reported household PA is developed by females (Martínez-Gómez, Guallar-Castillón, León-Muñoz, \& RodríguezArtalejo, 2014). Taking into consideration the results in previous studies with a prospective design, men should be encouraged to participate in other domains of PA apart from LTPA such as working, household activities and/or active transportation.

Total PA-Level decreases with age, confirming previous empirical evidence (Murtagh et al., 2015), but age is not statistically significant when analysing LTPA-Levels. Work status could play an important role in the reduction of Total PA with increasing age associated with retirement. It should be pointed out that, in our study, workers have a higher probability of doing physical activity in their daily-life but they have a lower significant probability of engaging in a great amount of LTPA, confirming other previous empirical evidence emphasising time restrictions (Palacios-Ceña et al., 2012, Downward \& Rasciute, 2015; Godfrey et al., 2014). For example, the study of Palacios-Ceña et al. (2012) revealed that the first reason for not practicing physical activity and sport at leisure time of Spaniards general population (15-74 years) was "I have no time due to working or study" Thus, working status is 
Table 4

Ordered Probits and Average Marginal Effects for LTPA-Level

\begin{tabular}{|c|c|c|c|c|c|c|c|c|c|c|c|}
\hline \multirow[t]{2}{*}{ Covariates } & \multicolumn{3}{|c|}{ Ordered Probits for LTPA METs } & \multicolumn{2}{|c|}{$\mathrm{y}=1<600 \mathrm{METs}(43.30 \%)$} & \multicolumn{2}{|c|}{$\begin{array}{c}\mathrm{y}=2 \text { 600-1499 METs } \\
(27.79 \%)\end{array}$} & \multicolumn{2}{|c|}{$\begin{array}{c}y=31500-2999 \\
\text { METs (18.62\%) }\end{array}$} & \multicolumn{2}{|c|}{$\begin{array}{c}\mathrm{y}=4 \\
(\mathbf{1 0 , 3 0 \% )}\end{array}$} \\
\hline & $\beta$ Coef. & t-Student & $p$ value & $d y / d x$ & SD & dy/dx & SD & $d y / d x$ & SD & $d y / d x$ & SD \\
\hline \multicolumn{12}{|l|}{ Social and demographic } \\
\hline Age & -.2301 & -1.37 & .172 & -.002 & .003 & -.000 & .000 & .001 & .001 & .001 & .001 \\
\hline $\mathrm{Age}^{2}$ & .0020 & 1.41 & .159 & & & & & & & & \\
\hline Male & .2961 & 3.39 & .001 & -.107 & .031 & .014 & .005 & .044 & .013 & .049 & .015 \\
\hline Marital status (Married) & -.1797 & -1.57 & .117 & .065 & .041 & -.009 & .006 & -.027 & .017 & -.030 & .019 \\
\hline \multicolumn{12}{|c|}{ Educational level completed } \\
\hline Sec. education & .2848 & 2.54 & .011 & -.103 & .040 & .014 & .006 & .043 & .017 & .047 & .019 \\
\hline Univ. education & .2289 & 1.74 & .082 & -.083 & .048 & .011 & .007 & .034 & .020 & .038 & .022 \\
\hline \multicolumn{12}{|l|}{ Income monthly $(\epsilon)$} \\
\hline $1001-1700$ & .0208 & 0.17 & .862 & -.008 & .043 & .001 & .006 & .003 & .018 & .003 & .020 \\
\hline $1701-2800$ & -.0643 & -0.51 & .609 & .023 & .046 & -.003 & .006 & -.010 & .019 & -.011 & .021 \\
\hline $2801-4000$ & -.2540 & -1.30 & .195 & .092 & .071 & -.012 & .010 & -.038 & .029 & -.042 & .032 \\
\hline$>4,000$ & -.3651 & -1.69 & .091 & .132 & .078 & -.018 & .011 & -.055 & .032 & -.060 & .036 \\
\hline Working status & -.2833 & -2.71 & .007 & .103 & .037 & -.014 & .006 & -.042 & .016 & -.047 & .018 \\
\hline \multicolumn{12}{|c|}{ Health and emotional well being } \\
\hline Health index & .4761 & 1.70 & .089 & -.173 & .101 & .023 & .014 & .071 & .042 & .078 & .046 \\
\hline Pain & -.1671 & -1.83 & .067 & .061 & .033 & -.008 & .005 & -.025 & .014 & -.027 & .015 \\
\hline Life satisfaction & .4236 & 3.97 & .000 & -.154 & .038 & .020 & .006 & .063 & .016 & .070 & .018 \\
\hline \multicolumn{12}{|l|}{ Extrinsic social support } \\
\hline Medical advice & .0508 & .59 & .554 & -.018 & .031 & .002 & .004 & .008 & .013 & .008 & .014 \\
\hline PA (partner) & .5484 & 5.48 & .000 & -.199 & .035 & .026 & .007 & .082 & .015 & .090 & .018 \\
\hline $\log L$ & & & & & -849.5530 & & & & & & \\
\hline Pseudo $R^{2}$ & & & & & .0530 & & & & & & \\
\hline Sample size & & & & & 709 & & & & & & \\
\hline
\end{tabular}

Note: METs represents METs $\cdot \min \cdot$ sem- $^{-}$

positively associated with Total PAbutnegatively with LTPA, suggesting that LTPA might increase after retirement (Godfrey et al., 2014; Touvier et al., 2010).

Graduates tend to develop a lower Total PA-Level than nongraduates but they are more active in LTPA-Level; this may reflect a higher awareness of health impact of PA and confirms previous evidence (Picorelli, Pereira, Pereira, Felício, \& Sherrington, 2014; Tiedemann, Sherrington, Close, \& Lord, 2011). This result offers alternative explanations about the positive relationship between educational levels and intensive levels of PA obtained previously by Casado-Pérez et al (2015b) and confirms the results obtained by Alonso-Blanco et al. (2012) about a positive relationship between LTPA and educational levels.

Self-perceived health represents a significant positive covariate for Total PA-Level, which partially confirms previous empirical evidence (Morrow-Howell et al., 2014; Romero et al., 2010). However, the degree of statistical significance is higher for Total PA than for LTPA. This result may reflect the fact that health-related and non-healthrelated factors affecting the level of PA could be explained by other documented limitations related to health and PAsuch as pain perception, fear and mood state (Palacios-Ceña et al., 2012; Bohórquez GómezMillán et al., 2014) and lets us to put into context the results obtained by previous studies in Spain (Alonso-Blanco et al., 2012). In addition, it could be argued that the relationship between Total PA-Level and health awareness could be closer than the potential relationship between LPTA and health awareness. In other words, LTPA-Level could be determined more by a wish of socialisation and enjoyment than for health considerations at this age interval. This argument might be confirmed by the positive and statistically significant relationship between life satisfaction and LTPA shown in Table 4. This result might have significant policy implications to boost PA. According to the results, the promotion of LTPA should focus attention on arguments regarding socialisation and/or life satisfaction.

The physician's (general practitioner, doctor or specialist) recommendation for PA was expected to be a positive significant covariate to meet PA requirements for health in older population. Nevertheless, in our study, this association is not significant. We might speculate that a general recommendation for PA is not enough, and population may need further indications (e.g., type or characteristics of exercise) or conditions of PA(alone-company, supervised-non-supervised) (Merom et al., 2012).

Having a partner engaged in PA is also positively correlated to Total
PA and LTPA-Levels, confirming previous empirical evidence and emphasising the relevance of peer influence (Cabane \& Lechner, 2014). The strength of this relationship might suggest that it would be interesting and efficient to focus on the couple/family level as well as the individual level. People with high incomes, who suffer pain or who are less satisfied with life tend to participate in LTPA to a lower degree than the rest. Unexpectedly, the level of household income is negatively associated with the level of LTPA; this reflects the relationship between this variable and time constraints in order to promote higher levels of LTPA. On the other hand, life satisfaction and pain seem to be only correlated with LTPA. Life satisfaction is positively associated with LTPA, confirming the results shown by Wicker and Frick (2015) while selfrated pain is negatively related with LTPA (only at $10 \%$ level of significance). This result reinforces the differences between Total PA and LTPA. Generally, pain is an habitual or frequent condition in older adults and in most occasions represents a sign or symptom associated with chronic diseases. Nevertheless, the pain dummy is only significant in PAdeveloped in leisure time, and lets us clarify some studies in which pain was classified as an internal barrier for PA participation (Franco et al., 2015).

Some limitations of this research should also be mentioned. A first potential limitation is related to the use of subjective measures of health status, well-being and physical activity levels. Although all these measures have been validated in many previous studies and countries, these variables might be susceptible to socially desirable responding. Another potential limitation is based on the nature of the data. The cross-sectional nature of the survey precludes us from drawing conclusive causal links among the key variables, and therefore, the causal relationship among them can only be hypothesised. For the future, using longitudinal designs will allow us to be more concise about causality. In addition, further research should consider extending the geographical scope of the sample by including other countries. Finally, another limitation of our study is the sample size, which has led us to consider as significant those variables with a significance level of $10 \%$

\section{Conclusions}

The present study adds to the literature by identifying significant socio-demographic, health and well-being variables associated with PA in individuals aged 50-70 years old. This analysis might contribute to the development of specific PA interventions tailored to the population between the fifties and seventies. The distinction of Total PA and LTPA 
allows us to develop specific policy measures. In most clinical practices, midlife and older patients are not offered specific exercise guidance. According to our results, some of the following factors should be considered in the development of these policy interventions: gender, education, working status, health and life satisfaction levels. For example, regarding women, social support seems necessary to reach minimum levels of LTPA. In the case of men, they should increase PA in other domains apart from LTPA. Also, the socialisation effect and the positive impact of the extrinsic social support variables might suggest the necessity to focus on the couple and family situation as well as at the individual level. By considering these factors and restrictions, higher levels of PA among older adults could be stimulated, with the associated health benefits, health assistance and costs reductions shown by previous literature in the population over 65 years of age (Ackermann et al., 2008).

\section{Acknowledgements}

This work was supported by the Spanish High Council of Sport under Grant (number 186/UPB10/12) and by the Regional Ministry of Economy and Employment of the Region of Asturias (FC-15-GRUPIN 14-064).

\section{References}

Ackermann, R. T., Williams, B., Nguyen, H. Q., Berke, E. M., Maciejewski, M. L., \& LoGerfo, J. P. (2008). Healthcare Cost Differences with Participation in a Community Based Group Physical Activity Benefit for Medicare Managed Care Health Plan Members. Journal of the American Geriatrics Society, 56(8), 14591465.

Ainsworth, B. E., Haskell, W. L., Whitt, M. C., Irwin, M. L., Swartz, A. M., Strath, S. J., . . Emplaincourt, P. O. (2000). Compendium of physical activities: an update of activity codes and MET intensities. Medicine and Science in Sports and Exercise, 32(9; SUPP/1), S498-S504.

Alonso-Blanco C, Palacios-Ceña D, Hernández-Barrera V, CarrascoGarrido P, Jiménez-García R, Fernández-de-Las-Peñas C. (2012). Trends in leisure time and work-related physical activity in the Spanish working population, 1987-2006. Gaceta Sanitaria, 26(3), 223-30.

Arem, H., Moore, S. C., Patel, A., Hartge, P., de Gonzalez, A. B., Visvanathan, K., ... Adami, H. O. (2015). Leisure Time Physical Activity and Mortality: A Detailed Pooled Analysis of the DoseResponse Relationship. JAMA Internal Medicine, 175(6), 959967.

Berg, B. K., Warner, S., \& Das, B. M. (2015). What about sport? A public health perspective on leisure-time physical activity. Sport Management Review, 18(1), 20-31.

Bohórquez Gómez-Millán M.R, Lorenzo Fernández M,. García A.J. (2014) Actividad física como promotor del autoconceptismo y la independencia personal en personas mayores. Revista Iberoamericana de Psicología del Ejercicio y el Deporte, 9(2), 533546.

Booth, M. L., Ainsworth, B. E., Pratt, M., Ekelund, U., Yngve, A., Sallis, J. F., \& Oja, P. (2003). International physical activity questionnaire: 12-country reliability and validity. Medicine \& Science in Sports \& Exercise, 195(9131/03), 3508-1381.

Cabane, C., \& Lechner, M. (2015). Physical activity of adults: a survey of correlates, determinants, and effects. Journal of Economics and Statistics, 235(4-5), 376-402.

Casado-Pérez, C., Hernández-Barrera, V., Jiménez-García, R., Fernández-de-las-Peñas, C., Carrasco-Garrido, P., López-deAndrés, A., ... Palacios-Ceña, D. (2015a). Time trends in leisure time physical activity and physical fitness in the elderly: Five-year follow-up of the Spanish National Health Survey (2006-2011). Maturitas, 80(4), 391-398.
Casado-Pérez C, Hernández-Barrera V, Jiménez-García R, Fernándezde-Las-Peñas C, Carrasco-Garrido P,Palacios-Ceña D. (2015b). Physical activity in adult working population: results from the European National Health Survey for Spain (2009). Atención Primaria, 47(9), 563-72.

Cesari, M., Cerullo, F.,Zamboni, V., Di Palma, R., Scambia, G, Balducci, L., .. . Gambassi, G. (2013). Functional status and mortality in older women with gynecological cancer. [Research Support, NonU.S. Gov't]. The Journals of Gerontology, Series A: Biological Sciences and Medical Sciences, 68(9), 1129-1133.

Cimarras-Otal, C., Calderón-Larrañaga,A., Poblador-Plou, B., GonzálezRubio, F., Gimeno-Feliu, L. A., Arjol-Serrano, J. L., \& PradosTorres, A. (2014). Association between physical activity, multimorbidity, self-rated health and functional limitation in the Spanish population. BMC Public Health, 14(1), 1170.

CIS. (2014). Barometer June 2014. Study 3029

Cohen, A., Baker, J., \& Ardern, C. I. (2016). Association Between Body Mass Index, Physical Activity, and Health-Related Quality of Life in Canadian Adults. Journal of Aging and Physical Activity, Jan 24(2), 32-38.

Curb, J. D., Ceria?Ulep, C. D., Rodriguez, B. L., Grove, J., Guralnik, J., Willcox, B. J., ... Chen, R. (2006). Performance-Based Measures of Physical Function for High?Function Populations. Journal of the American Geriatrics Society, 54(5), 737-742.

Chau, J. Y., Grunseit, A. C., Chey, T., Stamatakis, E., Brown, W. J., Matthews, C. E., ... van der Ploeg, H. P. (2013). Daily sitting time and all-cause mortality: a meta-analysis. PLoS ONE, November 13. doi: DOI: 10.1371 journal.pone. 0080000

Christensen, K., Doblhammer, G., Rau, R., \& Vaupel, J. W. (2009). Ageing populations: the challenges ahead. The Lancet, 374(9696), 1196-1208.

Downward, P., \& Rasciute, S. (2015). Exploring the covariates of sport participation for health: an analysis of males and females in England. Journal of Sports Science, 33(1), 67-76.

Franco, M. R., Tong, A., Howard, K., Sherrington, C., Ferreira, P. H., Pinto, R. Z., \& Ferreira, M. L. (2015). Older people's perspectives on participation in physical activity: a systematic review and thematic synthesis of qualitative literature. British Journal of Sports Medicine, 49(19), 1268-1276.

Frey, B. S., \& Stutzer, A. (2002). What can economists learn from happiness research? Journal of Economic Literature, 40(2): 402435.

Gebel, K., Ding, D., Chey, T., Stamatakis, E., Brown, W. J., \& Bauman, A. E. (2015). Effect of Moderate to Vigorous Physical Activity on All-Cause Mortality in Middle-aged and OlderAustralians. JAMA Internal Medicine, 175(6), 970-977.

Godfrey,A., Lord, S., Galna, B., Mathers, J.C., Burn, D. J., \& Rochester, L. (2014). The association between retirement and age on physical activity in older adults. Age and Ageing, 43(3), 386-393.

Hagströmer, M., Oja, P., \& Sjöström, M. (2006). The International Physical Activity Questionnaire (IPAQ): a study of concurrent and construct validity. Public Health Nutrition, 9(06), 755-762.

Haller, M., \& Hadler, M. (2006). How social relations and structures can produce happiness and unhappiness: An international comparative analysis. Social Indicators Research, 75(2), 169-216.

Hamrik, Z., Sigmundová, D., Kalman, M., Pavelka, J., \& Sigmund, E. (2014). Physical activity and sedentary behaviour in Czech adults: Results from the GPAQ study. European Journal of Sport Science, 14(2), 193-198.

Haskell, W. L., Lee, I.-M., Pate, R. R., Powell, K. E., Blair, S. N., Franklin, B.A., ... Bauman, A. (2007). Physical activity and public health: updated recommendation for adults from the American College of Sports Medicine and the American Heart Association. Circulation, 116(9), 1081.

Hurtig-Wennlöf, A., Hagströmer, M., \& Olsson, L. A. (2010). The International Physical Activity Questionnaire modified for the elderly: aspects of validity and feasibility. Public Health Nutrition, 
13(11), 1847.

INE. (2014). Proyección de la población de España 2014. Madrid.

Jia, H., \& Lubetkin, E. I. (2016). Impact of nine chronic conditions for US adults aged 65 years and older: an application of a hybrid estimator of quality-adjusted life years throughout remainder of lifetime. Quality of Life Research, 1-9.

Klijs, B., Nusselder, W. J., Looman, C. W., \& Mackenbach, J. P. (2011). Contribution of chronic disease to the burden of disability. PloS ONE, 6(9), e25325.

Lera-López, F., Garrués-Irisarri, M. A., Ollo-López, A., Sánchez Iriso, E., Cabasés Hita, J., \& Sánchez Santos, J. (2016 In press). Physical activity and self-perceived health among people aged 50 years and over. International Journal of Medicine and Science of Physical Activity and Sport.

López Munera R.C, Santos Campos M.A., Navarro Martínez A.V, ArévaloArévalo J.M, García Pinillos F., Latorre Román, P.A. (2016) Determinantes sociodemográficos y nivel de actividad física en la población de la provincia de Jaén mayor de 18 años Retos: Nuevas Tendencias en Educación Física, Deporte y Recreación, 29 (13-16)

Marques, E.A., Baptista, F., Santos, R., Vale, S., Santos, D. A., Silva,A. M., . . . Sardinha, L. B. (2014). Normative functional fitness standards and trends of Portuguese older adults: cross-cultural comparisons. Journal of Aging Physical Activity, 22(1), 126-137.

Martínez-Gómez, D., Guallar-Castillón, P., León-Muñoz, L. M., \& Rodríguez-Artalejo, F. (2014). Household physical activity and mortality in older adults: A national cohort study in Spain. Preventive Medicine, 61, 14-19.

Mateu, E. \& Casal, J. (2003). Tamaño de la muestra. Revista Epidemiológica de Medicina Preventiva, 1, 8-14.

Medina, C., Barquera, S., \& Janssen, I. (2013). Validity and reliability of the International Physical Activity Questionnaire among adults in Mexico. Revista Panamericana de Salud Pública, 34(1), 21-28.

Merom, D., Pye, V., Macniven, R., van der Ploeg, H., Milat, A., Sherrington, C., . . Bauman, A. (2012). Prevalence and correlates of participation in fall prevention exercise/physical activity by older adults. Preventive Medicine, 55(6), 613-617.

Mesters, I., Wahl, S., \& Van Keulen, H. M. (2014). Socio-demographic, medical and social-cognitive correlates of physical activity behavior among older adults (45-70 years): a cross-sectional study. $B M C$ Public Health, 14(1), 1.

Meyer, K., Rezny, L., Breuer, C., Lamprecht, M., \& Stamm, H. P. (2005). Physical activity of adults aged 50 years and older in Switzerland. Sozial-und Präventivmedizin, 50(4), 218-229.

Moore, L. V., Harris, C. D., Carlson, S. A., Kruger, J., \& Fulton, J. E. (2012). Trends in no leisure-time physical activity-United States, 1988-2010. Research Quarterly for Exercise and Sport, 83(4), 587-591.

Morrow-Howell, N., Putnam, M., Lee, Y. S., Greenfield, J. C., Inoue, M., \& Chen, H. (2014). An investigation of activity profiles of older adults. The Journals of Gerontology Series B: Psychological Sciences and Social Sciences, 69(5), 809-821.

Moschny, A., Platen, P., Klaaßen-Mielke, R., Trampisch, U., \& Hinrichs, T. (2011). Physical activity patterns in older men and women in Germany: a cross-sectional study. BMC Public Health, 11(1), 559.

Müller,A. M.,Ansari, P.,Ale Ebrahim, N., \& Khoo, S. (2015). Physical activity and aging research: a bibliometric analysis. Journal of aging and physical activity, JAPA In Press. doi: http://dx.doi.org/10.1123/ japa.2015-0188

Murtagh, E. M., Murphy, M. H., Murphy, N. M., Woods, C., Nevill, A. M., \& Lane, A. (2015). Prevalence and correlates of physical inactivity in community-dwelling older adults in Ireland. PLoS ONE, 10, e0118293-e0118293.

Paterson, D. H., Jones, G. R., \& Rice, C. L. (2007). Ageing and physical activity: evidence to develop exercise recommendations for older adults Journal of Public Health. Applied Physiology, Nutrition, and Metabolism, 32(S2E), S69-S108.
Palacios-Ceña D, Alonso-Blanco C, Jiménez-Garcia R, HernándezBarrera V, Carrasco-Garrido P, Pileño-Martinez E, Fernández-deLas-Peñas C. (2011). Time trends in leisure time physical activity and physical fitness in elderly people: 20 year follow-up of the Spanish population national health survey (1987-2006). BMC Public Health, 13(11):799.

Palacios-Ceña D, Fernandez-de-Las-Peñas C, Hernández-Barrera V, Jiménez-Garcia R, Alonso-Blanco C, Carrasco-Garrido P. (2012). Sports participation increased in Spain: a population-based time trend study of 21381 adults in the years 2000, 2005 and 2010. British Journal of Sports Medicine.,46(16):1137-9.

Picorelli, A. M. A., Pereira, L. S. M., Pereira, D. S., Felício, D., \& Sherrington, C. (2014). Adherence to exercise programs for older people is influenced by program characteristics and personal factors: a systematic review. Journal of Physiotherapy, 60(3), 151-156.

Prince, M. J., Wu, F., Guo, Y., Robledo, L. M. G, O'Donnell, M., Sullivan, R., \& Yusuf, S. (2014). The burden of disease in older people and implications for health policy and practice. The Lancet, 385(9967), 549-562.

Román-Viñas, B., Serra-Majem, L., Hagströmer, M., Ribas-Barba, L., Sjöström, M., \& Segura-Cardona, R. (2010). International Physical Activity Questionnaire: reliability and validity in a Spanish population. European Journal of Sport Science, 10(5), 297-304.

Román Viñas, B., Ribas Barba, L., Ngo, J., \& Serra Majem, L. (2012). Validación en población catalana del cuestionario internacional de actividad fisica. Gaceta Sanitaria, 10(5), 297-304.

Romero, S.; Carrasco, L.; Sañudo, B. y Chacón, F. . (2010). Actividad física y percepción del estado de salud en adultos sevillanos. Revista Internacional de Medicina y Ciencias de la Actividad Física y el Deporte 10(39) 380-392.

Santesmases Mestre, M. (2001). Dyane. Version 2. Diseño y análisis de encuentas en investigación social y de mercados. Ediciones Pirámide, Madrid.

Szende,A., Janssen, B., \& Cabases, J. (2014). Self-reported population health: an international perspective based on EQ-5D: Springer.

Taylor, A., Cable, N., Faulkner, G., Hillsdon, M., Narici, M., \& Van Der Bij,A. (2004). Physical activity and older adults: a review of health benefits and the effectiveness of interventions. Journal Sports Science, 22(8), 703-725.

Tiedemann, A., Sherrington, C., Close, J. C. T., \& Lord, S. R. (2011). Exercise and Sports ScienceAustralia Position Statement on exercise and falls prevention in older people. Journal of Science and Medicine in Sport, 14(6), 489.

Touvier, M., Bertrais, S., Charreire, H., Vergnaud, A.-C., Hercberg, S., \& Oppert, J.-M. (2010). Changes in leisure-time physical activity and sedentary behaviour at retirement: a prospective study in middle-aged French subjects. International Journal of Behavioral Nutrition and Physical Activity, 7(14.10), 1186.

Veenhoven, R. (2003). Hedonism and happiness. Journal of Happiness Studies, 4(4), 437-457.

Wang, M., \& Wong, M. S. (2014). Happiness and Leisure Across Countries: Evidence from International Survey Data. Journal of Happiness Studies, 15(1), 85-118.

Weijnen, T., Nieuwenhuizen, M., Oppe, S., Badia, X., Busschbach, J., Buxton, M., .. . Ohinmaa, A. (2006). A single European currency for EQ-5D health states: results from a six-country study. The European Journal of Health Economics, Sept 4(3), 222.

WHO. (2010). Global recommendations on physical activity for health. Geneva: World Health Organization, 8-10.

Wicker, P., \& Frick, B. (2015). The relationship between intensity and duration of physical activity and subjective well-being. The European Journal of Public Health, 25(5), 868-872.

Wooldridge, J. M. (2010). Econometric analysis of cross section and panel data. Cambridge, Massachusetts, London, England: The MIT press. 